\title{
LA EXPERIENCIA DEL ENCARCELAMIENTO EN ESPAÑA ${ }^{1}$
}

\author{
José Cid, Albert Pedrosa y Carmen Navarro \\ Universidad Autónoma de Barcelona
}

Title: The experience of imprisonment in Spain

\begin{abstract}
Resumen: Europa ha construido una política criminal humanitaria por lo que respecta al encarcelamiento a partir de tres principios básicos: limitación del uso de la prisión, normalización de la vida en la cárcel y reinserción como principal objetivo de la privación de libertad. Consecuentemente, parece relevante analizar si los diferentes sistemas penitenciarios europeos se acercan a este ideal. Partiendo de la existencia de una pluralidad de fuentes que nos acercan a la realidad del encarcelamiento, este trabajo se basa principalmente en una encuesta realizada a una muestra representativa de personas que experimentaron el encarcelamiento
\end{abstract}

1 Los resultados presentados en este artículo se enmarcan en sendos proyectos de investigación financiados, respectivamente, por el Ministerio de Economía y Competitividad: «Encarcelamiento y reincidencia» (DER2014-55315-P) y por el Ministerio de Ciencia, Innovación y Universidades: «Familia, desistimiento y reincidencia» (RTI2018097085-B-I00). Declaración de autoría en relación con la publicación: Los tres autores han acordado la estructura del artículo y revisado su versión final. José Cid es el director de la investigación que da origen al trabajo y ha sido el redactor del artículo. Albert Pedrosa ha elaborado los datos estadísticos. La revisión de la literatura previa ha sido realizada por Carmen Navarro y por José Cid. Agradecemos a la profesora Christy Visher, que nos dejara adoptar el cuestionario del proyecto Returning home: Understanding the Challenges of Prisoner Reentry, para nuestra investigación. También expresamos nuestra gratitud a la administración penitenciaria catalana (y en particular a Carles Soler, subdirector de programas de rehabilitación y a los directores y personal de los centros) su apoyo en la realización de la investigación y a los participantes de la investigación, por compartir su experiencia con nosotros. Finalmente, agradecemos las observaciones críticas de los evaluadores anónimos de la Revista de Derecho Penal y Criminología, que hemos tratado de atender en la versión final del artículo. 
en Cataluña. La investigación pone de relieve un avance positivo en los principios de normalización y reinserción con respecto a anteriores estudios. Sin embargo, en ambos principios se aprecian aspectos insatisfactorios que requieren la implementación de nuevas prácticas.

Palabras clave: Encarcelamiento; normalización; reinserción; encuesta.

Abstract: Europe has built a humanitarian criminal policy regarding imprisonment under three basic principles: limitation of the use of prison, normalization of prison life and reintegration as the main aim of the deprivation of freedom. Therefore, it seems relevant to assess whether European penitentiary systems fulfil this ideal. Moving from the repertory of sources that describe the reality of imprisonment, this paper is based mainly on a survey of a representative sample of people that have experienced imprisonment in Catalonia. The paper reveals a more positive fulfilment of the principles of normalization and reintegration in comparison with previous literature. However, concerning both principles there are some aspects of concern that require implementing new policies.

Keywords: Imprisonment; Normalization; Reintegration; Survey.

\section{Introducción ${ }^{2}$}

El encarcelamiento constituye una de las más graves privaciones legales de derechos que una persona puede sufrir, por lo que parece oportuno plantearse si el uso de esta pena respeta los estándares normativos europeos.

La política criminal europea está asentada en tres principios básicos. El primero de ellos es el de la limitación del uso de la prisión, de modo que ésta debe ser utilizada como último recurso y, en su caso, debe tener una duración razonable. El segundo de los principios es el relativo a la normalización de la vida en prisión, a tenor del cual, los derechos y la calidad de vida de las personas encarceladas deben aproximarse, lo más posible, a los derechos y la calidad de vida de los ciudadanos libres. De conformidad con el tercer principio, la reinserción se establece como el principal objetivo de la pena de prisión, de manera que las personas condenadas deben poder participar en programas de rehabilitación durante

2 En el trabajo utilizamos los términos «interno», «funcionario» y semejantes en sentido genérico, incluyendo a hombres y mujeres. En el caso de que nos refiramos específicamente a hombres o a mujeres lo hacemos constar. 
su encarcelamiento, así como recibir la asistencia necesaria para una exitosa transición a la comunidad (Cid y Andreu, 2017) ${ }^{3}$.

Uno de los cometidos más relevantes de la investigación penitenciaria consiste en considerar el respeto a los principios europeos relativos al encarcelamiento en cada país. A tal efecto, para evaluar el primero de los principios (la limitación del uso del encarcelamiento) podría acudirse a los datos oficiales que proporciona el sistema de justicia criminal (Dünkel, 2017). Sin embargo, tales datos pueden no ser suficientes para conocer adecuadamente la vigencia de los otros dos principios. Así, por lo que respecta al principio de normalización, algunas de sus dimensiones tienen un componente relacional que únicamente puede ser captado a partir de la opinión de las personas encarceladas. En cambio, las encuestas y/o entrevistas con aquéllas, pueden ser menos necesarias para evaluar el principio de reinserción, siendo suficientes los datos administrativos relativos a la participación en programas de rehabilitación y reinserción. Ahora bien, algunos aspectos que pueden ser relevantes para la reinserción, como la calidad de las relaciones con el personal dedicado a tal función, pueden requerir de datos directamente aportados por las personas encarceladas.

Por lo que respecta a los principios de normalización y reinserción, el conocimiento que tenemos acerca de la experiencia del encarcelamiento en España procede de las siguientes fuentes: en primer lugar, de informes de la administración penitenciaria y de las instituciones supervisoras; en segundo lugar, contamos con estudios basados en datos proporcionados por la administración; y, en tercer lugar, disponemos de estudios basados en encuestas y/o entrevistas a las personas encarceladas. Seguidamente, comentaremos someramente las citadas fuentes haciendo expresa mención de sus respectivas fortalezas y limitaciones.

Los informes de la administración penitenciaria se publican anualmente y proporcionan datos globales acerca de aspectos relevantes de la vida en prisión tales como la clasificación de las personas condenadas, su salud, programas de rehabilitación, trabajo en prisión o contactos con el mundo exterior (permisos, régimen abierto, libertad condicional) ${ }^{4}$. Algunos de estos datos pueden encontrarse en fuentes internacionales como Space I, así como en algunos estudios académicos que recogen sus

3 Nos remitimos a van Zyl Smith y Snacken (2009) y a Cid y Andreu (2017) para mostrar cómo estos tres principios se derivan de la jurisprudencia del Tribunal Europeo de Derechos Humanos, de las recomendaciones penológicas del Consejo de Europa, de los informes del Comité para la Prevención de la Tortura y de los Acuerdos marco de la UE en materia penal, en particular los relativos al reconocimiento mutuo de penas.

4 Vid. por ejemplo, el informe acerca del sistema penitenciario español de 2018 publicado por la Secretaría General de Instituciones Penitenciarias. Informe General 2018, que puede leerse en http://www.interior.gob.es/documents/642317/1202140/Informe_General_IIPP_2017_12615039X.pdf/9a3e9ad4-933d-422b9992-3a0d3686102d. 
principales resultados (Cid, 2005; Cutiño, 2015; Garcia-España y DíezRipollés, 2012; González, 2012; Navarro, 2018). De acuerdo con tales estudios, las personas encarceladas en España se encuentran mayoritariamente alojadas en instituciones penitenciarias modernas construidas durante la democracia (Cid, 2005). La población penitenciaria se compone de presos preventivos $(16 \%)$ y condenados $(84 \%)^{5}$. Por lo que respecta a las personas condenadas, pueden permanecer en centros cerrados, en los cuales pasan buena parte del día en las celdas individuales; en centros ordinarios, en los que tienen la posibilidad de participar en las actividades de prisión y, en centros abiertos, a los que los condenados asisten únicamente por las noches dado que durante el día suelen estar trabajando o realizando actividades en libertad. El régimen abierto también incluye a internos que no deben ir a prisión, ya que cumplen la restricción nocturna en su propio domicilio sometidos a control electrónico u otro medio de verificación. Los últimos datos de clasificación evidencian las siguientes cifras: 1,8\% (régimen cerrado); 73,1\% (régimen ordinario) y $18 \%$ (régimen abierto) ${ }^{6}$. Por lo general, en los centros ordinarios, las personas ocupan celdas dobles, no habiéndose apreciado problemas de superpoblación dado que el número de personas encarceladas ha descendido en los últimos años (Cid, 2020). En el régimen ordinario, además, las personas pueden ser alojadas en módulos de respeto o en unidades terapéuticas, en las que disfrutan de un mayor grado de autonomía, siempre que sigan un determinado código de conducta ya que los comportamientos violentos y el consumo de drogas no son aceptados en estas unidades. En el territorio de la Administración General del Estado, casi la mitad de las personas encarceladas en régimen ordinario se encuentran en módulos de respeto o unidades terapéuticas ${ }^{7}$, siendo la ubicación en módulos de respeto mayor entre la población penitenciaria femenina (Navarro, 2018).

Las personas condenadas en régimen ordinario gozan de la posibilidad de acceder a educación - incluyendo la educación universitaria a través de la Universidad Nacional Española a Distancia (UNED) - a formación profesional, a programas de tratamiento para condenados, entre otros, por agresiones sexuales, violentas, de violencia de género o con problemas de adicción y a trabajo remunerado. De todos modos, los datos acerca del número de las personas condenadas con voluntad de tomar parte en estos programas y que, efectivamente, hayan tenido acceso a los mismos no son fáciles de obtener a partir de los informes de la Administración Penitenciaria, exceptuando los relativos al número de

5 Datos de agosto de 2020 (Fuente: Instituciones Penitenciarias, Administración General del Estado).

6 Datos de agosto de 2020. Fuente: Instituciones Penitenciarias, Administración General del Estado. El restante 7\% corresponde a personas encarceladas no clasificadas.

7 Fuente: Informe General de la Instituciones Penitenciarias de 2018. En Cataluña, el número de módulos de respeto y de unidades terapéuticas es menor. 
encarcelados con trabajo en prisión que se aproxima al 45\% de las personas en prisiones de régimen ordinario ${ }^{8}$. Desde otra perspectiva, un $40 \%$ de las personas en régimen ordinario disfruta de permisos de salida ${ }^{9}$.

Los anteriores datos, suministrados por la Administración Penitenciaria, son útiles para evidenciar que la experiencia del encarcelamiento puede ser muy diversa en España, al depender de factores tales como el grado de clasificación, la participación en programas de tratamiento, la posibilidad de trabajar en prisión o el eventual disfrute de permisos de salida, entre otros. No obstante, para entender el impacto de dichas diferencias en las condiciones del encarcelamiento a efectos del cumplimiento de los principios de normalización y reinserción, debe ser tenida en cuenta la percepción de las personas encarceladas.

Otro importante instrumento para evaluar el cumplimiento de los estándares europeos viene dado por los informes de instituciones supervisoras, como es el caso del Defensor del Pueblo o del Comité para la Prevención de la Tortura (en adelante CPT) cuya principal misión reside, precisamente, en poner de manifiesto las debilidades del sistema penitenciario en el cumplimiento de aquellos principios ${ }^{10}$. Tales informes han evidenciado algunos aspectos respecto de los cuales el sistema penitenciario español no alcanzaría los estándares europeos, entre los que destacan: el exiguo nivel de actividades para encarcelados en régimen cerrado, la excesiva severidad de las medidas coercitivas, la necesidad de una investigación más rigurosa en los supuestos de denuncias de malos tratos y el número insuficiente de psiquiatras para atender a las personas encarceladas que padecen problemas de salud mental (Cid y Andreu, 2017). En todo caso el mejor trato de estas cuestiones está en la agenda de las administraciones penitenciarias ${ }^{11}$. Pese a la indudable relevancia de los informes emitidos por las mencionadas instituciones supervisoras, éstos no tienen como misión describir la experiencia del encarcelamiento sino denunciar malas prácticas del sistema y, conse-

8 Fuente: Informe General de la Instituciones Penitenciarias de 2018 y Memoria de la Consejería de Justicia de la Generalitat de Cataluña de 2018. De acuerdo con este último informe, en Cataluña el 60\% de la población penitenciaria en régimen ordinario apta para trabajar, estaba trabajando en prisión (p. 158) siendo el salario medio diario de 13 euros y la jornada laboral, por lo general, de 4 horas al día.

9 Datos correspondientes a Cataluña de 2017. Fuente: Administración Penitenciaria catalana.

10 Vid. por ejemplo el informe de 2016 acerca de la visita del CPT a España (CPT/Inf (2017) 34). Recuperado de: https://rm.coe.int/pdf/168076696b. O el Informe del Defensor del Pueblo Español de 2018 [Defensor del Pueblo, Informe anual, 2018] https://www.defensordelpueblo.es/informe-anual/informe-anual-2018/.

11 Véase el reciente informe del Comité para la Prevención de la Tortura, relativo a su visita a España en 2018, en el que se focalizó en prisiones de Cataluña, CPT/Inf (2020) 5. Recuperado de https://rm.coe.int/16809a5597 y la respuesta del Gobierno Español, CPT/ Inf (2020) 6. Recuperado de: https://rm.coe.int/16809a5253. 
cuentemente, deben ser complementadas con otra clase de información proveniente de las personas que experimentan el encarcelamiento.

La segunda fuente de datos relativos a la experiencia de encarcelamiento procede de estudios basados en datos administrativos centrados en algunos aspectos específicos de la vida en prisión, tales como la clasificación en régimen abierto (Capdevila, Pares, Ferrer, Luque y Torrecillas, 2005); la concesión de la libertad condicional (Capdevila, 2014; Tébar, 2005); el régimen disciplinario sancionador (Navarro, Ramos, Reynal, Líbano y Ruiz, 2011), las visitas en prisión (Cassà, 2015), la reincidencia (Capdevila, 2015), la efectividad de los programas de tratamiento (Redondo, 2017) y las condiciones de madres encarceladas (Navarro, 2018). Los resultados más destacados de las anteriores investigaciones serían los siguientes: algunas categorías de personas condenadas, como aquellas que están cumpliendo penas de corta duración y las personas extranjeras, tienen menos posibilidades de beneficiarse del régimen abierto y de la libertad condicional (Capdevila 2014, Tébar 2005); la mayoría de las personas encarceladas reciben visitas familiares (Cassà, 2015); la reincidencia es más elevada en el caso de personas que cumplen la totalidad de sus condenas y son puestas en libertad sin supervisión alguna (Capdevila, 2015); en las prisiones de jóvenes hay mayor número de expedientes disciplinarios que en las prisiones de adultos (Navarro et. al, 2011); el riesgo de reincidencia de agresores violentos o con adicción a las drogas se reduce cuando éstos pueden tomar parte en programas de rehabilitación de orientación cognitivo-conductual (Redondo, 2017); la monoparentalidad de muchas de las mujeres encarceladas puede desamparar a sus hijos durante el encarcelamiento (Navarro, 2018). Tal y como se ha mencionado, al estar estos estudios basados en datos administrativos, no sirven para recoger la experiencia subjetiva del encarcelamiento en aspectos relevantes como el bienestar subjetivo, la calidad de las relaciones, la percepción de la igualdad de trato o las expectativas de reinserción.

La última fuente de datos acerca de la experiencia del encarcelamiento en España la proporcionan los estudios que recogen la opinión de las personas encarceladas. Dentro de esta categoría, es preciso mencionar la serie de estudios llevada a cabo por un grupo de investigadores de la Universidad Pontificia de Comillas (Ríos y Cabrera, 1998 y 2002; Gallego, Ríos y Cabrera, 2010) que suponen las primeras encuestas realizadas en España sobre las condiciones de vida en las prisiones. En su último estudio, los citados autores obtuvieron una amplia muestra de personas encarceladas en prisiones de régimen ordinario en el territorio de la Administración General del Estado $(\mathrm{n}=1668)$. Sus resultados muestran que la experiencia del encarcelamiento puede ser más difícil para las personas extranjeras porque suelen tener menos apoyo social que los encarcelados españoles (Gallego et al., 2010, p. 132). Asimismo, los autores afirman que un tercio de las personas encarceladas con problemas de drogadicción podría no estar recibiendo tratamiento en prisión (Gallego et al., 2010, p. 113). Finalmente, por lo que respecta a las expectativas de 
reinserción, si bien la mayoría de encarcelados se muestran optimistas en lo relativo al trabajo y al hogar, hay una relevante minoría que es pesimista y un $10 \%$ que prevé estar sin hogar tras la excarcelación. Los autores concluyen que la reinserción puede ser un importante problema para parte de las personas encarceladas (Gallego et al., 2010).

Recientes estudios se han dedicado al análisis de la calidad de vida en prisión a partir de la encuesta MQPL (Midiendo la Calidad de la Vida en Prisión) desarrollada por el equipo liderado por Alison Liebling (2004) en el Reino Unido y que ha sido administrada en algunas prisiones de régimen ordinario españolas, de Cataluña (Rodríguez, Larrauri y Güerri, 2018), de Andalucía (Barquín, Cano y Calvo, 2019; Pozo, Navarro, Nakahira y Cutiño, 2018), así como en otras tres prisiones españolas (Enjuanes, 2020). Las principales conclusiones de dichos estudios revelan que la experiencia del encarcelamiento varía entre diferentes instituciones de una misma comunidad autónoma (Barquín et. al, 2019; Rodríguez et al., 2018); entre diversas unidades de una misma prisión (Pozo et al., 2018) e, incluso, entre unidades similares de diferentes prisiones (Enjuanes, 2020). Así, según el estudio de Rodríguez et al. (2018), la calidad de vida de las personas encarceladas depende en gran medida de las condiciones de organización de la prisión, de las relaciones entre encarcelados y el personal penitenciario y de las ayudas para la reinserción. Corroborando los hallazgos de Gallego et al. (2010), uno de los aspectos peor valorados de la prisión es la posibilidad de recibir un tratamiento de calidad en el caso de condenados adictos a las drogas (Barquín et al., 2019).

Por lo que respecta específicamente a las mujeres encarceladas, Almeda (2002) llevó a cabo un estudio en una prisión de régimen ordinario catalana. Las conclusiones de su investigación cualitativa (con entrevistas a 37 mujeres presas y 34 miembros del personal penitenciario) ponían de relieve que las condiciones del encarcelamiento femenino eran discriminatorias comparadas con las de los hombres: las mujeres estaban alojadas en la peor parte de la prisión y tenían menos posibilidades de participar en programas de tratamiento que, además, reafirmaban los tradicionales roles de género; tenían, asimismo, menor probabilidad de obtener un trabajo remunerado en prisión y eran consideradas por el personal penitenciario como más conflictivas que los hombres. Algunos años después, un grupo de investigadores liderados por Giménez-Salinas (Giménez-Salinas, Riera, Botella y Marteache, 2006) tomó parte en el proyecto europeo International study of women imprisonment (Dünkel, Kerstermann y Zolondeck, 2006). En el marco del citado proyecto, administraron una encuesta acerca de las condiciones del encarcelamiento en dos prisiones catalanas, obteniendo 89 participantes. Si bien los resultados de la investigación del grupo de Giménez-Salinas no incluyen una comparativa con hombres encarcelados, sí pusieron de manifiesto que la mayoría de los aspectos concernientes a prisión fueron respondidos de manera negativa (calidad de las celdas, comida, ambiente en prisión, educación y oportunidades de formación, 
actividades de ocio y preparación de la excarcelación). Únicamente el trato dispensado por el personal penitenciario y las posibilidades de contacto familiar fueron mayoritariamente respondidos en sentido positivo. Otra encuesta más reciente, llevada a cabo en prisiones andaluzas, reveló que la mayor preocupación de las mujeres encarceladas se centra en sus hijos (Mapelli, Herrera y Sordi, 2013). Por su parte, Almeda y Ballesteros-Pena (2015) y Ballesteros-Pena (2018) analizaron en sendas investigaciones el uso de los Módulos de Respeto, en los que la mayoría de mujeres encarceladas se encuentra en los centros penitenciarios dependientes de la Administración General del Estado (Navarro, 2018, 28). A juicio de las autoras, los Módulos de Respeto no responden a las necesidades de las mujeres encarceladas (Almeda y Ballesteros-Pena, 2015; Ballesteros-Pena, 2018, 460). Finalmente, Jiménez-Bautista (2016) administró una encuesta a una amplia muestra de mujeres encarceladas en España $(n=538)$ al efecto de verificar si éstas se sentían discriminadas con respecto a los hombres encarcelados. A tenor de sus resultados, las mujeres no se consideran discriminadas excepto en lo atinente a las posibilidades de trabajo penitenciario y a las salidas programadas.

\section{Investigación realizada}

\subsection{La muestra}

Los datos utilizados en este estudio fueron recogidos, principalmente, a partir de un proyecto de investigación dedicado al análisis de la relación existente entre el encarcelamiento y la reincidencia ${ }^{12}$. El objetivo de la recogida de datos residía en obtener una muestra representativa de personas encarceladas que acabaran de cumplir sus condenas en el plazo de un año en Cataluña. Los participantes fueron reclutados en 10 prisiones de régimen ordinario, en 6 prisiones de régimen abierto y en 4 servicios sociales penitenciarios de seguimiento de personas liberadas condicionalmente, cubriendo todas las instituciones correccionales de la comunidad autónoma. La muestra fue obtenida en cuatro fases distintas entre abril de 2016 y julio de 2017.

La administración penitenciaria catalana elaboró un listado de personas penadas que iban a cumplir sus condenas en cada una de las dis-

12 Se trata del proyecto de investigación «Encarcelamiento y Reincidencia», que está siendo desarrollado por investigadores de la Universidad Autónoma de Barcelona y que contempla tres fases de investigación: una encuesta realizada en los años 2016-2017, en la que se basa el presente trabajo, unas entrevistas de seguimiento tras la liberación, realizadas entre 2017 y 2019 a 37 personas de la muestra, y un estudio de reincidencia con toda la muestra cerrado en octubre de 2020. Para elaborar la encuesta de la investigación tomamos como referencia el cuestionario del proyecto «Returning home», (Visher y O'Connell, 2012) y realizamos diversas adaptaciones teóricas y contextuales. 
tintas instituciones elegidas en un período de 6 meses. Por su parte, el equipo de investigadores tuvo contacto con los encarcelados y liberados condicionales en los últimos meses de sus condenas (4 meses antes de la fecha de cumplimiento de la sentencia como media). El personal penitenciario distribuyó una carta elaborada por el equipo investigador a las personas elegibles en la que se explicaba el objetivo de la investigación. Estas personas fueron invitadas a asistir a una reunión en la que los investigadores solicitaron su consentimiento informado. Los que prestaron su asentimiento rellenaron un cuestionario auto-administrado, con la ayuda de los investigadores en caso de solicitarla. Los cuestionarios fueron mayoritariamente completados en las aulas de las instalaciones de los centros elegidos (prisiones y servicios sociales penitenciarios de seguimiento de los liberados condicionales) sin la supervisión del personal de los centros penitenciarios.

En total, obtuvimos una relación de 1394 personas encarceladas y liberadas condicionales. El personal penitenciario contactó con 1072 personas a fin de invitarlas a participar en la investigación. Las restantes 322 personas habían sido o bien transferidas a diferentes instituciones o bien consideradas no disponibles para participar por diversas causas tales como enfermedad, trabajo o permisos, entre otras. De las 1072 personas invitadas a participar en la investigación, 538 (50,2\%) de ellas mostraron su voluntad de intervenir en la misma. La respuesta afirmativa fue más elevada entre las prisiones de régimen ordinario $(57,5 \%)$ y de régimen abierto $(58,3 \%)$ que en los centros de servicios sociales de seguimiento de los liberados condicionales $(33,7 \%)$. La disparidad en los porcentajes parece debida al hecho que las personas que se encontraban en libertad condicional debían ser contactadas individualmente y citadas en el centro de servicios sociales correspondiente para rellenar el cuestionario, lo cual redujo la participación.

Los cuestionarios fueron completados en una media de 75 minutos y cada participante fue compensado con 10 euros por el tiempo invertido.

La Tabla 1 muestra la distribución de la muestra obtenida y su comparación con la población de referencia en función del género, la edad, la nacionalidad y el tipo de liberación. 
Tabla 1. Comparativa entre población y muestra

\begin{tabular}{|c|c|c|c|c|c|}
\hline & \multicolumn{2}{|c|}{$\begin{array}{l}\text { Población cuya } \\
\text { condena expiraba en } \\
2016 \text { en Cataluña* }\end{array}$} & \multicolumn{2}{|c|}{ Muestra } & \multirow{2}{*}{$\begin{array}{c}\text { Diferencias } \\
\text { Puntos } \\
\text { porcentuales }\end{array}$} \\
\hline & $\mathrm{N}$ & $\%$ & $\mathrm{~N}$ & $\%$ & \\
\hline \multirow{3}{*}{$\begin{array}{l}\text { Género } \\
\text { Hombres } \\
\text { Mujeres }\end{array}$} & & & & & \\
\hline & 2833 & 92,0 & 488 & 90,9 & $-1,1$ \\
\hline & 247 & 8,0 & 50 & 9,1 & 1,1 \\
\hline \multirow{3}{*}{$\begin{array}{c}\text { Edad } \\
\text { Menor de } 35 \\
\text { Mayor de } 35\end{array}$} & & & & & \\
\hline & 1236 & 40,1 & 206 & 38,3 & $-1,8$ \\
\hline & 1844 & 59,9 & 332 & 61,7 & 1,8 \\
\hline \multirow{3}{*}{$\begin{array}{c}\text { Nacionalidad } \\
\text { Español } \\
\text { Extranjero }\end{array}$} & & & & & \\
\hline & 1842 & 59,8 & 328 & 61,0 & 1,2 \\
\hline & 1238 & 40,2 & 210 & 39,0 & $-1,2$ \\
\hline \multirow{2}{*}{$\begin{array}{l}\text { Liberación } \\
\text { Régimen cerrado u } \\
\text { ordinario }(* *)\end{array}$} & & & & & \\
\hline & 1737 & 56,4 & 337 & 62,6 & 6,2 \\
\hline \multirow{2}{*}{$\begin{array}{l}\text { Régimen abierto } \\
\text { Libertad condicional }\end{array}$} & 566 & 18,4 & 100 & 18,6 & 0,2 \\
\hline & 778 & 25,3 & 101 & 18,8 & $-6,4$ \\
\hline Total & 3080 & 100,0 & 538 & 100,0 & \\
\hline
\end{tabular}

* Fuente: Administración catalana de servicios penitenciarios.

$(* *)$ Nota: de las 337 personas de la muestra en régimen ordinario o cerrado, 16 estaban en régimen cerrado, lo que supone un 3\% de la muestra.

En referencia a la investigación previa sobre la experiencia del encarcelamiento en España que hemos resumido en el epígrafe anterior, el mérito de este nuevo estudio radica en que es representativo de la población que cumple una pena de prisión. La investigación previa sobre la experiencia de las personas condenadas en el cumplimiento de la pena de prisión había quedada circunscrita a personas que estaban cumpliendo su condena en régimen ordinario o en régimen cerrado. Pero ello supone una muestra sesgada de la población penitenciaria. Aunque es cierto, como puede observarse en la tabla 1, que el $56.4 \%$ de los condenados son liberados desde el primer o segundo grado de tratamiento, y se tratará de personas que en general habrán cumplido toda su condena en estos regí- 
menes, existe un $43,6 \%$ que son liberados de manera escalonada, pasando por el tercer grado, o por éste y la libertad condicional. De ahí que la recogida de la muestra únicamente en prisiones de régimen ordinario presente el inconveniente de la infrarrepresentación de las personas que cumplen parte de su condena en régimen abierto o en libertad condicional.

\subsection{Indicadores para evaluar los principios de normalización $y$ de reinserción}

En virtud del principio de normalización, recogido en el art. 5 de las Reglas Penitenciarias Europeas, «la vida en prisión se ajustará tanto como sea posible a los aspectos positivos de la vida fuera de prisión» ${ }^{13}$. Ahora bien, teniendo en cuenta que la encuesta en la que la presente investigación se basa no iba dirigida a verificar el cumplimiento del principio de normalización, únicamente presentaremos datos relativos a algunos aspectos de este principio. En este sentido, conviene advertir que algunos de los considerados relevantes por la doctrina como el nivel de autonomía de las personas encarceladas (Pratt y Erikson, 2011; Reiter, Sexton y Sumner, 2018), no han sido objeto de análisis en esta investigación. Tampoco lo han sido otros aspectos fundamentales del principio de normalización como la calidad de los servicios proporcionados a las personas encarceladas (salud, educación, actividades) (Van Zyl Smit y Snacken, 2009). Sin embargo, los aspectos del principio de normalización que sí hemos analizado en esta investigación, tales como el hecho de ser tratado de manera justa y con el debido respeto por el personal y las autoridades penitenciarias, el disfrute de un entorno seguro, la obtención de un trabajo o el mantenimiento de los lazos sociales, a nuestro juicio son indicadores fundamentales del principio que preconiza que la vida en prisión ha de aproximarse lo más posible a la vida en libertad.

Uno de los aspectos relevantes del principio de normalización reside en ser tratado de manera digna, esto es, con respeto, recibiendo un trato equitativo y con debida consideración por parte del personal y las autoridades penitenciarias (van Zyl Smit y Snacken, 2009). Debe tenerse en cuenta para valorar la importancia de este principio que las personas encarceladas únicamente conseguirán mejorar la calidad de sus vidas (salud, comida, alojamiento, actividades de ocio, participación en programas, trabajo y contacto con el exterior, entre otros) por mediación del personal de la Administración Penitenciaria. En esta misma línea, la encuesta MQPL, desarrollada por Alison Liebling y otros investigadores en 2004, utilizada también por diversos investigadores en España, sostiene que la relación existente entre el personal penitenciario y las

13 Recomendación Rec (2006) del Comité de Ministros a los Estados Miembros sobre las Reglas Penitenciarias Europeas. 
personas encarceladas es una de las dimensiones de la calidad de la vida en prisión.

En segundo término, preguntamos a los participantes acerca de la seguridad en prisión y es que, a nuestro juicio, ésta constituye una importante dimensión del principio de normalización, si bien no suele ser considerada como uno de los elementos integrantes de dicho principio. Sin embargo, debe tenerse en cuenta que las prisiones pueden llegar a ser lugares en los que la victimización y los sentimientos de inseguridad son elevados (Bottoms, 1999). Es por ello que pensamos que el principio de normalización requiere que la seguridad se aproxime en la mayor medida posible a la que existe en la sociedad. Con este objetivo, medimos tanto la victimización directa ejercida sobre las personas encarceladas como la eventual victimización indirecta. A fin de construir la escala de victimización indirecta, adaptamos la «Escala de ambiente negativo en prisión» desarrollada por Listwan, Sullivan, Agnew, Cullen y Colvin (2011, p. 24), en la que los participantes son preguntados acerca de la frecuencia de conductas violentas y otros delitos entre personas encarceladas. Respecto de esta escala, procedimos a añadir preguntas que dan cuenta, en su caso, de la percepción del encuestado de trato injusto por parte del personal penitenciario hacia las personas encarceladas.

El tercer aspecto considerado para evaluar el nivel de normalización de la vida en prisión fue la posibilidad de tener un trabajo remunerado durante el cumplimiento de la condena y el nivel de satisfacción con el trabajo realizado. En este sentido, parece evidente que el trabajo constituye la manera normal de proveer a las necesidades tanto propias como familiares y así lo reconoce el art. 26 de las Reglas Penitenciarias Europeas, que establece que el trabajo deberá ser proporcionado por las autoridades penitenciarias.

Finalmente, considerando el amplio acuerdo existente acerca de que una de las dimensiones del principio de normalización reside en que el encarcelamiento no puede implicar una ruptura en la vida familiar de las personas condenadas ${ }^{14}$, verificamos el cumplimiento del referido principio preguntando a los condenados sobre si habían podido mantener su relación con la familia durante la condena. Este apoyo familiar no es únicamente relevante a efectos del principio de normalización, sino que también contribuye al fomento de narrativas de desistimiento (Cid y Martí, 2012; Martí y Cid, 2015).

Por lo que respecta al principio de reinserción, interpelamos a los participantes, en primer lugar, acerca de si habían participado en programas de tratamiento que, de acuerdo con investigaciones criminológicas,

14 Véase artículo 24,1 de las Reglas Penitenciarias Europeas en el que se establece que los presos deben poder comunicar lo más posible con sus familiares y otras personas de la comunidad. 
sirven para prevenir la reincidencia (Mackenzie, 2006). Les pedimos que nos indicaran si aquellos programas habían sido de utilidad para acrecentar sus habilidades y mejorar su calidad de vida en prisión. Dada la relevancia en la literatura de la idea conforme a la cual los condenados deben estar debidamente asistidos para preparar su salida de prisión (Travis, 2005), preguntamos a los participantes, asimismo, si habían contado con una persona de referencia entre el personal penitenciario (Liebling et al., 2019) y, en caso afirmativo, si había sido útil en los diferentes aspectos relativos a la preparación del regreso a la vida en libertad. Además, teniendo en cuenta la prometedora literatura sobre la importancia de la continuidad asistencial entre la prisión y la comunidad a fin de maximizar las posibilidades de una exitosa reinserción (Jonson y Cullen, 2015), recogimos en la muestra también el uso de los mecanismos de transición (permisos, régimen abierto y libertad condicional). Finalmente, tuvimos presente la literatura sobre desistimiento que afirma que una perspectiva optimista acerca de la reinserción tendrá una influencia en los resultados de ésta (Burnett, 1992; Doeckhie, Dirkzwager y Nieuwbeerta, 2017; Howerton, Burnett, Byng y Campbell, 2009; Marti y Cid, 2015; Visher y O'Connell, 2012) y por consiguiente utilizamos la escala, desarrollada por Visher y O'Connell (2012) en la investigación Returning Home, en la entrevista anterior a la puesta en libertad. Esta escala analiza las expectativas individuales acerca de la vida tras el cumplimiento de la condena en un conjunto de 14 ítems que se relacionan con cinco dimensiones: relaciones con la familia, aceptación social, salud, situación económica y conductas desviadas e ilegales.

\subsection{Método}

La exposición de los resultados será dividida en tres secciones distintas. En las dos primeras nos ocuparemos del principio de normalización y del de reinserción. Mostraremos los resultados de todas las preguntas relevantes de la encuesta realizando una dicotomización entre las respuestas que reflejan un cumplimiento de los principios de normalización y de reinserción y aquéllas que evidencian la falta de realización de aquellos principios. Comparando porcentajes, podremos llegar a conclusiones acerca del cumplimiento de los principios analizados en nuestra muestra. Con carácter general, evaluamos favorablemente el indicador considerado cuando la mayoría de los encuestados (más del 50\%) realizan una valoración positiva, y lo evaluamos negativamente cuando la mayoría de los encuestados realiza una valoración negativa. Somos conscientes de que este criterio que utilizamos puede ser criticado, bajo el argumento de que el ideal de los principios señalados es que su respeto sea universal. Sin embargo, lo utilizamos porque creemos que permite distinguir entre aspectos a mejorar (que son valorados de manera positiva por una mayoría de personas pero que debe trabajarse para que esta valoración se extienda 
a la minoría insatisfecha) y aspectos críticos (que son valorados de manera negativa por la mayoría de internos, que deberían ser de atención prioritaria en las políticas penitenciarias). Finalmente, en la tercera sección verificaremos si, en algunos aspectos de estas dimensiones, podemos confirmar la afirmación en virtud de la cual algunas minorías en prisión, como mujeres y personas extranjeras, pueden sufrir peores condiciones por lo que respecta a la normalización y a la reinserción. A tal efecto, buscaremos diferencias significativas- entre hombres y mujeres y entre personas extranjeras y nacionales- en cada uno de los ítems considerados.

\section{Resultados}

\subsection{Principio de normalización}

\subsubsection{Trato digno}

Examinamos si los participantes habían sido tratados de manera digna, esto es, con respeto, de manera justa y con la debida consideración por parte del personal y las autoridades penitenciarias. Los resultados (tabla 2) muestran que la mayoría de los encuestados se han sentido tratados con respeto y de manera justa, aunque es cierto que las mayorías son exiguas en algún ítem, por ejemplo sólo la mitad de los participantes apreciaron que el personal penitenciario mostró interés en sus asuntos. Por otra parte, existe un ítem, concretamente el relativo a la motivación del personal penitenciario por resolver los problemas de las personas condenadas, que ha sido mayoritariamente evaluado de manera negativa y que supone una importante excepción a la valoración positiva de este aspecto.

Tabla 2. Trato digno recibido por personal y autoridades penitenciarias

\begin{tabular}{|c|c|c|}
\hline & $\begin{array}{c}\text { Siempre/ } \\
\text { Normalmente } \\
\%\end{array}$ & $\begin{array}{c}\text { Raramente/ } \\
\text { Nunca } \\
\%\end{array}$ \\
\hline He recibido un trato respetuoso & 70,5 & 29,5 \\
\hline $\begin{array}{c}\text { He sido tratado peor que el resto de } \\
\text { condenados }\end{array}$ & 25,5 & 74,5 \\
\hline Mis derechos han sido respetados & 64,3 & 35,7 \\
\hline He podido exponer mis peticiones & 62,5 & 37,5 \\
\hline $\begin{array}{c}\text { He recibido respuesta a los asuntos } \\
\text { planteados }\end{array}$ & 53,6 & 46,4 \\
\hline
\end{tabular}




\begin{tabular}{|c|c|c|}
\hline & $\begin{array}{c}\text { Siempre/ } \\
\text { Normalmente } \\
\%\end{array}$ & $\begin{array}{c}\text { Raramente/ } \\
\text { Nunca } \\
\%\end{array}$ \\
\hline $\begin{array}{c}\text { Ha sido fácil recurrir las decisiones } \\
\text { negativas para mi }\end{array}$ & 52,1 & 47,9 \\
\hline Ha escuchado mis puntos de vista & 56,5 & 43,5 \\
\hline $\begin{array}{c}\text { Se ha esforzado por dar respuesta a los } \\
\text { asuntos planteados }\end{array}$ & 46,4 & 53,6 \\
\hline
\end{tabular}

\subsubsection{Seguridad}

El segundo de los aspectos hace referencia a la percepción de seguridad durante la estancia en prisión. La tabla 3 refleja si los participantes han sido victimizados a lo largo de su condena. Los resultados indican que, para la mayoría de los participantes, el encarcelamiento ha sido una experiencia segura. En cambio, una minoría de participantes sí ha sufrido algún tipo de victimización.

Tabla 3. Victimización directa

\begin{tabular}{|c|c|c|}
\hline & $\begin{array}{c}\text { A menudo/ } \\
\text { Algunas veces }\end{array}$ & $\begin{array}{c}\text { Raramente/ } \\
\text { Nunca }\end{array}$ \\
\hline $\begin{array}{c}\text { Me han insultado o humillado otros in- } \\
\text { ternos }\end{array}$ & 20,4 & 79,6 \\
\hline $\begin{array}{c}\text { He sido golpeado o agredido por otros } \\
\text { internos }\end{array}$ & 10,9 & 89,1 \\
\hline Me han amenazado otros/as internos & 16,5 & 83,5 \\
\hline Otros internos me han robado & 13,4 & 86,6 \\
\hline
\end{tabular}

El segundo parámetro de medición de la seguridad utilizada ha sido el de la victimización indirecta. A tal efecto, inquirimos a los participantes acerca del ambiente percibido mientras se encontraban en prisión a partir de diversas preguntas que hacían referencia a diversas situaciones de victimización. Los resultados (tabla 4) muestran que la mayoría de los participantes perciben la cárcel como un lugar inseguro, principalmente a resultas de la violencia interpersonal entre las personas encarceladas. 
Tabla 4. Victimización indirecta

\begin{tabular}{|c|c|c|}
\hline $\begin{array}{c}\text { Los internos tienen miedo de ser } \\
\text { agredidos por otros internos }\end{array}$ & $\begin{array}{c}\text { A menudo/ } \\
\text { Algunas veces }\end{array}$ & $\begin{array}{c}\text { Raramente/ } \\
\text { Nunca }\end{array}$ \\
\hline $\begin{array}{c}\text { Las personas débiles se someten a otros } \\
\text { internos }\end{array}$ & 74,8 & 25,2 \\
\hline $\begin{array}{c}\text { Las personas son amenazadas por } \\
\text { internos la primera vez que entran en } \\
\text { prisión }\end{array}$ & 53,7 & 26,2 \\
\hline $\begin{array}{c}\text { Las personas sufren agresiones por parte } \\
\text { de otros internos }\end{array}$ & 67,5 & 36,3 \\
\hline $\begin{array}{c}\text { Existen peleas entre bandas } \\
\text { Trato poco respetuoso por parte del } \\
\text { personal y autoridades penitenciarias }\end{array}$ & 40,7 & 59,3 \\
\hline $\begin{array}{c}\text { Hay amenazas por parte del personal y } \\
\text { autoridades penitenciarias }\end{array}$ & 56,8 & 43,2 \\
\hline $\begin{array}{c}\text { Se producen agresiones por parte del } \\
\text { personal y autoridades penitenciarias }\end{array}$ & 40,7 & 54,8 \\
\hline $\begin{array}{c}\text { Se adoptan decisiones injustas por parte } \\
\text { del personal y autoridades penitenciarias }\end{array}$ & 66,2 & 59,3 \\
\hline
\end{tabular}

En definitiva, teniendo en cuenta ambas dimensiones de victimización, podemos concluir que, si bien únicamente una minoría ha sido directamente victimizada, la mayoría de los participantes consideran que la cárcel no es un entorno seguro a resultas principalmente de la violencia interpersonal existente entre los internos.

\subsubsection{Trabajo}

En lo atinente al trabajo remunerado, los resultados de nuestro cuestionario indican que la mayoría de los participantes (74.5\%) trabajaron durante el cumplimiento de sus condenas. Asimismo, para la mayoría de los mismos, el trabajo fue de utilidad para la mejora de sus aptitudes laborales ${ }^{15}$.

15 La percepción acerca de la utilidad del trabajo es más elevada respecto del trabajo realizado en la comunidad (sea en régimen abierto o en libertad condicional) (90\%) que 


\subsubsection{Relaciones familiares}

Preguntamos, asimismo, a los participantes si habían podido mantener la relación con su familia a lo largo del cumplimiento de sus condenas. Los resultados (Tabla 5) muestran cómo la mayoría de los participantes mantuvo el vínculo con la familia, que se erige, a su vez, como fuente de apoyo instrumental y emocional.

Tabla 5. Apoyo familiar

\begin{tabular}{|c|c|c|}
\hline $\begin{array}{c}\text { Me he sentido acompañado por mi familia } \\
\text { durante la condena }\end{array}$ & $\begin{array}{c}\text { Siempre/ } \\
\text { Bastante }\end{array}$ & $\begin{array}{c}\text { Raramente/ } \\
\text { Nunca }\end{array}$ \\
\hline $\begin{array}{c}\text { Mi familia me ha prestado apoyo económico } \\
\text { durante mi condena }\end{array}$ & 65 & 21,9 \\
\hline $\begin{array}{c}\text { Me he sentido querido/a por mi familia } \\
\text { durante la condena }\end{array}$ & 83,6 & 16,4 \\
\hline $\begin{array}{c}\text { Mi familia se ha sacrificado por mi durante mi } \\
\text { condena }\end{array}$ & 73,8 & 26,2 \\
\hline $\begin{array}{c}\text { Me siento en deuda con mi familia por el } \\
\text { apoyo que me ha prestado durante la condena }\end{array}$ & 71,3 & 28,7 \\
\hline $\begin{array}{c}\text { Mi familia me ha pedido que cambiara } \\
\text { Mi familia me ha motivado a participar en } \\
\text { actividades durante mi condena }\end{array}$ & 71,4 & 28,6 \\
\hline
\end{tabular}

\subsection{Principio de reinserción}

\subsubsection{Participación en programas de tratamiento}

Interpelamos a los participantes sobre su participación en programas de rehabilitación, así como acerca de la utilidad de los mismos. Concretamente, preguntamos sobre cinco tipos distintos de programas implementados en el sistema penitenciario catalán: programas de deshabituación de alcohol o drogas, de mejora de la salud mental, educativos, de formación profesional y programas cognitivo-conductuales para personas condenadas por delincuencia violenta. La práctica totalidad de los participantes $(98,6 \%)$ afirmaron haber tenido la oportunidad de

del llevado a cabo dentro de prisión $(69,9 \%)$. 
participar en los programas que más se ajustaban a sus necesidades y, en esta misma línea, el 95,6\% de los encuestados de la muestra realizó alguno de los programas mencionados. Por lo que respecta a la utilidad de los mismos (Tabla 6), la mayoría de los participantes consideró que los programas en los que había intervenido fueron de utilidad tanto en lo relativo a la consecución de sus objetivos específicos (superación de adicciones, mejoría de la salud mental, de las aptitudes educativas, de la formación profesional, del autocontrol y de las habilidades para la resolución de conflictos) como en lo atinente al incremento de su calidad de vida durante el encarcelamiento.

Tabla 6. Utilidad de los programas de tratamiento

\begin{tabular}{|c|c|c|c|}
\hline & & $\begin{array}{c}\text { Totalmente } \\
\text { a favor/ } \\
\text { a favor }(\%)\end{array}$ & $\begin{array}{c}\text { Totalmente } \\
\text { en contra/ } \\
\text { en contra } \\
(\%)\end{array}$ \\
\hline \multirow{2}{*}{$\begin{array}{c}\text { Adicción a las } \\
\text { drogas }\end{array}$} & Superación de la adicción & 68,7 & 31,3 \\
\hline & Mejora de la calidad de vida & 69,1 & 30,9 \\
\hline \multirow{2}{*}{ Salud mental } & Mejoría de la salud mental & 78 & 22 \\
\hline & Mejora de la calidad de vida & 76,4 & 23,6 \\
\hline \multirow{2}{*}{ Educación } & $\begin{array}{c}\text { Mejoría habilidades en } \\
\text { educación }\end{array}$ & 87,3 & 12,7 \\
\hline & Mejora de la calidad de vida & 83,9 & 16,1 \\
\hline \multirow{2}{*}{$\begin{array}{l}\text { Formación } \\
\text { profesional }\end{array}$} & Mejora aptitudes laborales & 91,8 & 8,2 \\
\hline & Mejora de la calidad de vida & 88,5 & 11,5 \\
\hline \multirow{2}{*}{$\begin{array}{l}\text { Conducta } \\
\text { violenta }\end{array}$} & Mejora de las habilidades & 85,4 & 14,6 \\
\hline & Mejora de la calidad de vida & 68,5 & 31,5 \\
\hline
\end{tabular}

\subsubsection{Apoyo profesional para la reinserción}

La mayoría de los participantes $(66,9 \%)$ afirmaron haber contado con la asistencia de un miembro del personal del centro penitenciario (funcionario de prisión o personal de rehabilitación como educador, trabajador social, psicólogo, entre otros) o de entidades colaboradoras en la 
fase final de sus condenas de cara al proceso de reinserción. La Tabla 7 muestra que la persona de referencia es valorada positivamente por los participantes tanto en lo concerniente al apoyo emocional como al instrumental para una exitosa reinserción. Únicamente una de las dimensiones del proceso de reinserción (búsqueda de vivienda) fue evaluada de manera negativa por la mayoría de los participantes.

Tabla 7. Apoyo profesional para la reinserción ${ }^{16}$

\begin{tabular}{|c|c|c|}
\hline & $\begin{array}{l}\text { De acuerdo } \\
(\%)\end{array}$ & $\begin{array}{c}\text { En desacuerdo } \\
(\%)\end{array}$ \\
\hline $\begin{array}{l}\text { 1. La persona de referencia me ha tratado } \\
\text { como merecía }\end{array}$ & 85,4 & 14,6 \\
\hline $\begin{array}{l}\text { 2. La persona de referencia ha mostrado } \\
\text { interés en mi proceso de reinserción }\end{array}$ & 81,4 & 18,6 \\
\hline $\begin{array}{l}\text { 3. La persona de referencia ha manifestado } \\
\text { confianza en mis posibilidades de } \\
\text { reinserción }\end{array}$ & 83,2 & 16,8 \\
\hline $\begin{array}{l}\text { 4. La persona de referencia me ha dado } \\
\text { consejos útiles para gestionar la reinserción }\end{array}$ & 78,3 & 21,7 \\
\hline $\begin{array}{l}\text { 5. La persona de referencia me ha sometido } \\
\text { a una vigilancia excesiva }\end{array}$ & 27,3 & 72,7 \\
\hline $\begin{array}{l}\text { 6. La persona de referencia me ha ayudado } \\
\text { a mejorar mi formación }\end{array}$ & 84,2 & 15,8 \\
\hline $\begin{array}{l}\text { 7. La persona de referencia me ha ayudado } \\
\text { a mejorar las relaciones con mi familia }\end{array}$ & 64,4 & 35,6 \\
\hline $\begin{array}{l}\text { 8. La persona de referencia me ha ayudado } \\
\text { a mejorar mis posibilidades de inserción } \\
\text { laboral }\end{array}$ & 72,7 & 27,7 \\
\hline $\begin{array}{l}\text { 9. La persona de referencia me ha ayudado } \\
\text { a encontrar vivienda }\end{array}$ & 27,7 & 72,3 \\
\hline
\end{tabular}

16 En las preguntas 1 y 5 , «de acuerdo» engloba «siempre» $\mathrm{y}$ «normalmente» mientras que «en desacuerdo» agrupa "raramente» $\mathrm{y}$ «nunca». Por su parte, en las preguntas 2,3 y 4 , en "de acuerdo" se incluye "mucho» y "bastante» y en "en desacuerdo", poco o nada. Finalmente, en las cuatro últimas preguntas, «de acuerdo» agrupa «totalmente de acuerdo» $\mathrm{y}$ «de acuerdo» $\mathrm{y}$ «en desacuerdo», «en desacuerdo» $\mathrm{y}$ «totalmente en desacuerdo». 


\subsubsection{Salida escalonada}

Poco más de la mitad de los participantes de la muestra (51.6\%) se beneficiaron de permisos de salida durante el cumplimiento de sus condenas y únicamente una minoría $(37,4 \%)$ disfrutaron en la última parte de sus condenas del régimen abierto o de la libertad condicional.

\subsubsection{Expectativas de reinserción}

Preguntamos a los participantes acerca de la probabilidad que se produjera alguna situación negativa una vez producida la excarcelación. Como puede observarse en la Tabla 8, los participantes se mostraron bastante optimistas por lo que respecta a sus expectativas de reinserción. Incluso en las cuestiones más problemáticas —situación económica y trabajo- aproximadamente dos tercios de los participantes de la muestra manifestaron tener expectativas favorables ${ }^{17}$.

Tabla 8. Expectativas de reinserción ${ }^{18}$

\begin{tabular}{|c|c|c|}
\hline & $\begin{array}{c}\text { Improbable/ } \\
\text { Muy improbable } \\
\%\end{array}$ & $\begin{array}{c}\text { Probable/ } \\
\text { Muy probable } \\
\%\end{array}$ \\
\hline $\begin{array}{c}\text { Ser amenazado, acosado o agredido } \\
\text { por un miembro de su familia o por la } \\
\text { persona con la que se plantea vivir }\end{array}$ & 95,2 & 4,8 \\
\hline No tener relación con su familia & 89,4 & 10,6 \\
\hline No tener relación con sus hijos & 87,6 & 12,4 \\
\hline No ser socialmente aceptado & 74,2 & 25,8 \\
\hline No poder mantenerse económicamente & 70,6 & 29,4 \\
\hline No gozar de buena salud & 80,1 & 19,9 \\
\hline No ganar dinero suficiente para & 61,7 & 38,3 \\
\hline mantenerse & 86,2 & 13,8 \\
\hline
\end{tabular}

17 En el trabajo de Cid, Pedrosa, Ibáñez y Martí (2021) analizamos qué factores de la experiencia del encarcelamiento contribuyen al optimismo respecto de la reinserción.

18 El cuestionario incluía sendas preguntas acerca de las relaciones con los hijos y las respuestas fueron únicamente incluidas en los cálculos de aquellos participantes que tenían hijos. 


\begin{tabular}{|c|c|c|}
\hline & $\begin{array}{c}\text { Improbable/ } \\
\text { Muy improbable } \\
\%\end{array}$ & $\begin{array}{c}\text { Probable/ } \\
\text { Muy probable } \\
\%\end{array}$ \\
\hline No tener o poder mantener su trabajo & 66,7 & 33,3 \\
\hline $\begin{array}{c}\text { No poder mantener a sus hijos } \\
\text { menores de edad }\end{array}$ & 77,4 & 22,6 \\
\hline No poder pagar sus deudas & 77,6 & 22,4 \\
\hline Consumir drogas ilegales & 83,6 & 16,4 \\
\hline Volver a delinquir & 89,8 & 10,2 \\
\hline Ingresar de nuevo en prisión & 88,9 & 10,1 \\
\hline
\end{tabular}

Pese a mostrarse optimistas en términos generales, la mayoría de los participantes $(66,1 \%)$ vislumbraron, al menos, una situación problemática que podría llegar a producirse y que podría conducirlos a reincidir. La tabla 9 ofrece la prevalencia de estas situaciones problemáticas entre la muestra. Teniendo en cuenta los resultados de la tabla 8 y 9 , podemos concluir que los participantes son conscientes de los problemas que van a experimentar al alcanzar la libertad y, sin embargo, la mayoría se muestran confiados en superarlos.

Tabla 9. Problemas al alcanzar la libertad

\begin{tabular}{|c|c|}
\hline Problema & Prevalencia (\%) \\
\hline Acercarme a malas compañías & 29,3 \\
\hline No tener trabajo & 27,2 \\
\hline No tener dinero suficiente para mantenerme & 21,2 \\
\hline Consumir drogas & 18,4 \\
\hline No tener apoyo de mi familia & 15,6 \\
\hline Consumir alcohol & 13,8 \\
\hline No tener un lugar para vivir & 12,1 \\
\hline Sentirme deprimido & 10,9 \\
\hline No ver a mis hijos & 10,7 \\
\hline No tener apoyo de mis amigos & 5 \\
\hline
\end{tabular}




\subsection{Las minorías en prisión}

En el siguiente epígrafe, contrastaremos resultados de anteriores investigaciones acerca de las peores condiciones de encarcelamiento de algunas minorías como las mujeres y las personas extranjeras.

\subsubsection{Mujeres}

En lo atinente al principio de normalización, en ninguno de los aspectos analizados (relaciones de las encarceladas con el personal y las autoridades penitenciarias, seguridad, trabajo y apoyo familiar) se aprecian diferencias significativas entre los hombres y las mujeres de la muestra. Preciso es reconocer, en cuanto al apoyo de la familia, que el porcentaje es mayor respecto de los hombres (3.13) que de las mujeres (2.82) en una escala de 1-4. Sin embargo, tal diferencia no es significativa. Únicamente en una de las preguntas («Me siento en deuda con mi familia por el apoyo que me ha prestado durante mi condena») se aprecian diferencias significativas por cuanto las mujeres se sienten menos deudoras para con sus familias que los hombres por el apoyo recibido.

Por lo que respecta al principio de reinserción, la única diferencia significativa entre hombres y mujeres radica en el hecho que más mujeres $(84.8 \%)$ que hombres $(65.2 \%)$ contaron con el apoyo de una persona de referencia entre el personal del centro penitenciario o perteneciente a alguna entidad colaboradora en la preparación de su salida de prisión. En cuanto al resto de aspectos analizados (utilidad de los programas de rehabilitación, salida escalonada ${ }^{19}$ y expectativas a la salida) sólo se detectaron algunas diferencias significativas. Así, en relación con la participación en programas de tratamiento destinados a la mejora de la salud mental, la de las mujeres fue mayor que la de los hombres. También por lo que respecta a las expectativas a la salida, el riesgo de ser victimizadas por algún miembro de la familia es superior entre las mujeres que entre los hombres.

\subsubsection{Extranjeros}

En cuanto al principio de normalización, se aprecian algunas diferencias significativas entre personas nacionales y extranjeras, aunque no siempre en el sentido esperado. Las personas extranjeras afirman haber sido tratadas con respeto por parte del personal y autoridades penitenciarias en una proporción más elevada que las españolas. A su vez, el

19 Las mujeres disfrutaron de más permisos de salida que los hombres $(51.1 \%$ frente a un $48 \%$ ) y de salidas anticipadas al cumplimiento total de la condena (46\% frente al $36.5 \%)$. No obstante, las diferencias no son significativas. 
personal penitenciario intentó resolver sus peticiones en mayor medida de la que afirmaron las personas nacionales.

Por lo que respecta a la victimización indirecta, en todos los ítems de la escala, excepto el relativo a peleas entre bandas (vid. tabla 4), aparecen diferencias significativas que denotan que las personas extranjeras perciben un ambiente más seguro en prisión que las nacionales.

En lo relativo al apoyo familiar, como era de esperar, las personas extranjeras se sienten menos acompañadas por sus familias, aunque éstas han pedido un cambio en el participante en mayor proporción que las familias de las personas nacionales. Ambas diferencias son significativas. Por el contrario, no se aprecian diferencias significativas en cuanto al acceso al trabajo en prisión entre personas extranjeras y nacionales.

Asimismo, aparecen diferencias significativas entre ciudadanos extranjeros y nacionales desde el punto de vista del principio de reinserción. Las diferencias indican que las personas extranjeras tienen menos posibilidades de beneficiarse del apoyo de una persona de referencia entre el personal penitenciario, así como de gozar de salidas de prisión a la comunidad, ya sean permisos de salida $(55.2 \%$ de personas nacionales y $38.2 \%$ de extranjeras) o salida anticipada al cumplimiento total de la condena (42.1\% de personas nacionales frente al 30\% de las extranjeras). En sentido contrario, en cuanto a las expectativas a la salida de prisión, pueden observarse diferencias significativas que ponen de manifiesto que las personas nacionales se sienten más preocupadas que las extranjeras en lo concerniente a salud, drogas y pago de deudas. Sin embargo, no se aprecia diferencia alguna atendiendo a la participación en los programas de tratamiento

\section{Discusión}

\subsection{Conclusiones}

Este estudio utilizó una encuesta realizada a una muestra representativa de personas condenadas a una pena de prisión en Cataluña a fin de evaluar si la experiencia del encarcelamiento en España se adecúa a los principios de normalización y reinserción que, como es sabido, constituyen los pilares de la política criminal europea, junto con el principio de reducción del uso de la prisión (Cid y Andreu, 2017). Ambos principios resultan parte muy relevante del ideal humanitario de la pena de prisión. El principio de normalización quiere señalar que la persona privada de libertad debe poder gozar de condiciones de vida semejantes a las de las personas en libertad. Es cierto que la condena habrá restringido el derecho a la libertad ambulatoria, pero el resto de derechos individuales (a la dignidad, a la intimidad, a la seguridad, a la salud, a la educación, 
a la vida familiar, entre muchos otros) deben ser respetados en prisión, de la misma manera que fuera de ella. La importancia del principio de normalización no estriba sólo en la idea de que los derechos humanos no se detienen en las puertas de las prisiones, sino también en tratar de minimizar al máximo posible los efectos dañinos del encarcelamiento en el bienestar personal (Lerman, 2009). Por otra parte, el principio de reinserción, parte de que la persona habrá podido delinquir a causa de unos déficits que se debe tener oportunidad de superar en prisión y, por otra, que el hecho de haber sido encarcelado podrá ser un obstáculo para que la persona pueda vincularse socialmente tras la condena y, por ello, el sistema penitenciario debe ayudar en este proceso.

En primer lugar, este trabajo ha estudiado la realización del principio de normalización. Debe destacarse de nuevo que algunos aspectos de este principio, como la autonomía de los internos o la calidad de los servicios prestados (salud, alimentación, actividades) no han sido analizados. En relación, por tanto, a las dimensiones de este principio analizadas (trato digno, seguridad, trabajo y relación con el mundo exterior) podemos llegar a las siguientes conclusiones.

Sobre la base del criterio de valoración utilizado - valorar como positivo un ítem cuando más del 50\% de internos lo aprueba- podemos decir que la mayoría de aspectos analizados del principio de normalización se alcanzan, aunque con un importante margen de mejora, que queda fijado en su aprobación universal. Así, las relaciones entre las personas condenadas y el personal y las autoridades penitenciarias han sido consideradas por la doctrina como criterio clave de la calidad de vida en prisión (Liebling, 2004; Liebling et al., 2019) y de nuestra encuesta se desprende que la mayoría de las personas condenadas reciben un trato digno por parte del personal y autoridades penitenciarias, esto es, se sienten tratadas con respeto, de manera justa y con la debida consideración, aunque existe una excepción importante con la motivación del personal penitenciario a responder a los asuntos planteados por los internos, que recibe una valoración negativa. Otras dimensiones del principio de normalización se entienden también satisfechas: la mayoría de las personas condenadas tienen la posibilidad de llevar a cabo un trabajo remunerado durante el cumplimiento de sus penas, lo que incrementa, por un lado, la calidad de vida de aquéllas y por otro, supone un cierto alivio a los costes del encarcelamiento para las familias. Además, la mayoría de las personas encarceladas recibe el apoyo de sus familiares.

En segundo lugar, y pese a la realización en general positiva del principio de normalización, nuestra investigación destaca una dimensión muy relevante de este principio que recibe una evaluación negativa: la seguridad en las prisiones. Si bien la vicitmización directa es sufrida por una minoría de internos, en cifras semejantes a las reportadas el contexto internacional (Bottoms, 1999), las personas encuestadas describieron el ambiente en la prisión en que cumplieron condena como el 
de un lugar como inseguro puesto que tres cuartas partes de la muestra respondieron que las personas condenadas sienten miedo de ser atacadas por otras personas encarceladas (vid. tabla 4). Asimismo, cabe tener presente que vivir en un entorno inseguro no es solo relevante a efectos del principio de normalización. También lo es por lo que respecta al desistimiento dado que la tensión inherente a aquel ambiente podría incrementar las probabilidades de reincidencia una vez en libertad (Listwan et al., 2011).

En tercer lugar, podemos afirmar que la mayoría de los aspectos del principio de reinserción se cumplen de manera positiva a tenor de las respuestas de los participantes de nuestra encuesta, aunque algunos dimensiones de este principio tienen un margen importante de mejora. En este sentido, por ejemplo, el derecho a participar en programas de rehabilitación se satisface prácticamente de manera completa: más del 95\% de los participantes encuestados tomaron parte en alguno de los programas de tratamiento que, además, consideraron de utilidad tanto para cubrir sus necesidades criminógenas cuanto para incrementar su calidad de vida en prisión ${ }^{20}$. Desde esta misma perspectiva, la mayoría de personas condenadas, aun siendo conscientes de los problemas que deberían afrontar a la salida y que podrían conducirlos a la reincidencia, pudieron ser asistidas en sus procesos de preparación para la vida en libertad por una persona de referencia en prisión que les proporcionó apoyo emocional e instrumental. Finalmente, la mayoría de los condenados finalizaron sus condenas con optimismo acerca de sus posibilidades de sortear situaciones negativas una vez en libertad.

Consecuentemente, podemos concluir que la mayoría de condenados cumplieron sus condenas habiendo participado en programas de tratamiento, disfrutando de apoyo para preparar su vida en libertad y con una visión optimista sobre su futuro en la comunidad. En concordancia con la literatura revisada en la introducción de este estudio, los tres aspectos coadyuvan a reducir la tasa de reincidencia y a una positiva integración social tras la condena. La valoración positiva no debe hacer olvidar que existe un margen de mejora importante en estas dimensiones del principio de reinserción, en particular en el apoyo profesional para la reinserción.

En cuarto lugar, debemos realizar una valoración negativa de un aspecto del principio de reinserción: sólo una minoría de personas gozan de una transición escalonada a la comunidad. Debe tenerse en cuenta que la regulación europea aboga explícitamente por la transición gradual como forma normal de cumplimiento de las condenas de prisión, pues existe

20 Nuestros resultados, por tanto, no corroboran los obtenidos a partir de datos administrativos en una investigación anterior, basados no obstante en datos de la Administración General del Estado (Cutiño, 2015). 
evidencia que la continuidad de intervención entre la prisión y la comunidad ayuda a la reinserción (Jonson y Cullen, 2015) ${ }^{21}$. Sin embargo, solo una minoría de los participantes de nuestra muestra llegó a beneficiarse de una salida escalona y supervisada. Teniendo en cuenta que los condenados que no cumplieron de manera íntegra sus condenas en prisión recibieron más ayuda que aquéllos que sí lo hicieron (Cid y Ibáñez, 2019), parece lógico que esta falta de regreso gradual a la libertad definitiva pueda incrementar el riesgo de reincidencia (Capdevila, 2015).

Como quinta conclusión destacaremos, confirmando los resultados obtenidos por Jiménez-Bautista (2016), que tampoco los nuestros apoyan la idea conforme a la cual las mujeres encarceladas estarían discriminadas con respecto a los hombres privados de libertad. Efectivamente, en algunos aspectos, como el ser asistidas por una persona de referencia en su salida en libertad, parecen en una mejor situación que los hombres. Ahora bien, preciso es reconocer que sí apreciamos diferencias significativas en otros aspectos tales como una mayor participación de las mujeres en los programas de tratamiento para mejorar la salud mental o una expectativa más elevada de ser víctima de violencia por parte de algún miembro de su familia una vez en libertad, lo que podría sugerir que la experiencia del encarcelamiento puede ser más penosa para las mujeres que para los hombres (Mapelli, Herrera, Sordi, 2013; Navarro, 2018, p. 103) 22 .

Nuestra última conclusión va dedicada a las personas extranjeras. No hemos hallado evidencia alguna de discriminación hacia los condenados no nacionales por lo que respecta al principio de normalización. Al contrario, las personas extranjeras tienen una mejor relación con el personal y autoridades penitenciarias y se sienten más seguras que las nacionales. De todos modos, la encuesta sí confirma que las personas extranjeras gozan de menos oportunidades de cara a la reinserción: un número inferior de condenados extranjeros, respecto de los nacionales, cuenta con la asistencia de una persona de referencia en el proceso de transición de la prisión a la comunidad y disfruta, asimismo, de menos permisos

21 La Rec (2002) 22 del Comité de Ministros en materia de libertad condicional establece en su art. 4 «A fin de reducir los dañinos efectos del encarcelamiento y promover la reinserción de los condenados en condiciones que garanticen la seguridad de la comunidad, la ley debe posibilitar la libertad condicional a todos los condenados, incluidos aquellos condenados a penas de cadena perpetua».

22 No nos hemos planteado en este estudio, aunque reconocemos su importancia, la idea expresada por Almeda y Ballesteros (2015) y Ballesteros (2018) conforme a la cual el encarcelamiento femenino debe ser no sólo valorado teniendo en cuenta la igualdad respecto de los hombres en la misma situación sino también siendo sensible a las necesidades específicas de las mujeres encarceladas. En la línea de la opinión de Almeda y Ballesteros, véase el reciente informe del Comité para la Prevención de la Tortura, relativo a su visita a España en 2018, que se focalizó en prisiones de Cataluña, el cual demanda mayor perspectiva de género en la intervención penitenciaria. CPT/Inf (2020) 5 Recuperado de https://rm.coe.int/16809a5597. 
de salida y de salidas escalonadas que los nacionales. La idea acerca de la discriminación padecida por las personas extranjeras condenadas a una pena de prisión fue expresada hace tiempo por los investigadores (Tébar, 2005), ha sido, también, admitida por los propios profesionales del medio penitenciario (Ibàñez, 2019) y parece vinculada a las políticas de deportación de inmigrantes con antecedentes penales impidiendo que el sistema penitenciario cumpla su objetivo de reinserción (Cid y Ibàñez, 2019; García-España, 2012).

\subsection{Limitaciones}

La investigación presentada adolece de ciertas limitaciones. La primera de ellas es debida a la realización de la encuesta en las instituciones penitenciarias catalanas por lo que no podemos obviar que, de haber administrado la encuesta en el conjunto de España, los resultados podrían ser distintos. De todos modos, teniendo en cuenta los elementos de armonización (legislación, instalaciones, personal y programas de tratamiento) que ambos sistemas comparten, no creemos que las diferencias, en su caso, pudieran ser sustanciales. La segunda de las limitaciones encuentra explicación en el sistema de recogida de la muestra que no permitió incluir en la misma a aquellas personas que estaban cumpliendo una pena de prisión de corta duración ${ }^{23}$, especialmente por impago de multa (lo que representa aproximadamente a un $20 \%$ de las personas encarceladas que cumplen sus condenas en un promedio de 40 días) (Capdevila, 2015, 116). De este modo, la investigación no refleja la experiencia del encarcelamiento de las personas condenadas a penas privativas de libertad de escasa duración. Finalmente, nuestra encuesta iba dirigida a analizar el impacto de la experiencia del encarcelamiento en la reincidencia y, en consecuencia, no recabamos información acerca de algunos aspectos de la vida en prisión que podrían ser fundamentales para profundizar sobre el cumplimiento del principio de normalización pero que, de acuerdo con la teoría, no estaban ligados a la reincidencia.

Ahora bien, pese a las señaladas limitaciones, consideramos que las principales fortalezas de nuestra investigación estriban, por una parte, en haber recogido y analizado una muestra representativa de personas condenadas a pena de prisión en una de las comunidades autónomas españolas con más población y, por otro, en haber utilizado una encuesta capaz de reflejar adecuadamente los aspectos estudiados relativos a los principios de normalización y de reinserción.

23 Las personas condenadas a penas privativas de libertad de corta duración cumplían condena en prisiones destinadas a presos preventivos, en las cuales creemos el personal penitenciario tiene un menor contacto con los internos y en los que la tasa de consentimientos obtenidos para participar en la investigación fue muy baja. 


\subsection{Implicaciones}

El principio de normalización conlleva la necesidad de acciones que mejoren la percepción de la seguridad de las personas encarceladas en España. De acuerdo con algunas investigaciones recientes (Pozo et al., 2018; Enjuanes, 2020), el cumplimiento en los módulos de respeto del sistema penitenciario de la Administración General del Estado permitiría un mayor grado de cumplimiento del principio de normalización que el cumplimiento de la condena en régimen ordinario. Precisamente, una de las características de estos módulos de respeto reside en no permitir comportamiento violento alguno. Otras experiencias internacionales también han resaltado que un importante elemento de la calidad de vida en prisión consiste en asumir que la violencia es un comportamiento inaceptable (Liebling et al., 2019). Los módulos de respeto, sin embargo, no han estado exentos de críticas ${ }^{24}$. Ahora bien, a nuestro juicio, el principio de normalización implica que la persona encarcelada pueda tener la oportunidad de vivir en un lugar en el cual la violencia no sea un comportamiento admisible. A fin de hacer efectivo el principio de normalización creemos que los módulos de respeto deberían existir en cualquier prisión ordinaria y, en esta misma línea, que cualquier persona condenada debería tener una oportunidad real de cumplir su condena en un módulo de este tipo.

Desde la perspectiva del principio de reinserción, es preciso señalar que, si bien la mayoría de sus elementos se cumplen de manera satisfactoria en el sistema penitenciario catalán, únicamente una minoría de las personas condenadas se beneficia de una salida gradual y continúa gozando de asistencia en la transición de la cárcel a la comunidad. De acuerdo con un previo análisis de la muestra, se sugirió que la persona de referencia en la reinserción podría tener un papel más activo en prisión a fin de incrementar el número de personas que podrían beneficiarse de una salida anticipada (Pedrosa, 2019). Otra sugerencia para incrementar el número de personas que podrían acogerse a una salida anticipada hace referencia al cambio del marco legal de la libertad condicional, de manera que ésta pueda producirse de manera automática en un momento concreto de la condena (Cid y Tébar, 2010). El perfeccionamiento del sistema de salida gradual pasa también por atender a la población encarcelada extranjera que adolece de peores ratios de asistencia por parte de la persona de referencia en el proceso de transición a la libertad, goza de menos permisos de salida y es clasificada en menor proporción en régimen abierto y libertad condicional. La reali-

24 Almeda y Ballesteros (2015) y Ballesteros (2018) se muestran críticas con la filosofía de los módulos de respeto para mujeres porque «la implementación de las prácticas de clasificación y de responsabilización refuerzan las tradicionales características del tratamiento femenino tales como la disciplina, el control y la obediencia, además de estar asentados en estereotipos de género, raza y nacionalidad»(Ballesteros, 2018, 460). 
dad muestra que solo un pequeño porcentaje de condenados extranjeros son, finalmente, deportados (García-España, 2012) y, consecuentemente, esa realidad debe ser tenida en cuenta a fin de no restringir las políticas orientadas a una exitosa reinserción de las personas extranjeras (Ibàñez, 2019).

\section{Referencias bibliográficas:}

Almeda, E. (2002). Corregir y castigar: El ayer y hoy de las cárceles de mujeres. Barcelona: Ediciones Bellaterra.

Almeda, E., y Ballesteros-Pena, A. (2015). Políticas de igualdad en las cárceles del siglo XXI. Avances, retrocesos y retos en la práctica del encarcelamiento femenino. Praxis Sociológica, 19, 161-186.

Ballesteros-Pena, A. (2018). Responsibilisation and female imprisonment in contemporary penal policy: 'Respect Modules' ('Módulos de Respeto') in Spain. Punishment \& Society, 20(4) 458-476.

Barquín, J., Cano, M. A., y Calvo, M. (2019). Treatment, reintegration, and quality of prison life: perception by inmates. International Journal of Offender Therapy and Comparative Criminology, 63(13), 2291-2317.

Воттомs, А. (1999). Interpersonal violence and social order in prisons. Crime and Justice, 26, 205-280.

BuRnetT, R. (1992). The dynamics of recidivism. Oxford: Oxford Centre for Criminological Research.

Capdevila, M. (coord.) (2014). La libertad condicional en Cataluña Barcelona: Centro de Estudios Jurídicos y Formación Especializada.

CAPDEVILA, M. (coord.) (2015). Tasa de reincidencia penitenciaria 2014. Barcelona: Centro de Estudios Jurídicos y Formación Especializada.

Capdevila, M., Parés, R., Ferrer, M., Luque, E., y Torrecillas, M. (2005). La clasificación inicial en régimen abierto de los condenados a prisión. Barcelona: Centro de Estudios Jurídicos y Formación Especializada.

CASSÀ, N. (2015). Les visites familiars a presos com a element reductor de la reincidència. Barcelona: Centro de Estudios Jurídicos y Formación Especializada.

CID, J. (2005). The penitentiary system in Spain. The use of imprisonment, living conditions and rehabilitation. Punishment \& Society, 7(2), 147-166.

CID, J. (2020). El futuro de la prisión en España. Revista Española de Investigación Criminológica, 18, 1-32. 
Cid, J., Andreu, A. (2017). European criminal policy and Spanish prison practice: understanding confluences and gaps. En: T. Daems y L. Robert (Eds.), Europe in prisons, (pp. 255-289). London: Palgrave-Macmillan.

CID, J. y IвÀÑEZ, A. (2019). Prisoner resettlement in Spain -Good practices for early-released prisoners and prisoners lost in transition that fully serve their sentence. En F. Dünkel, I. Pruin, A. Storgaard, y J. Weber (Eds.), Prisoner Resettlement in Europe, (pp. 313-327). Abingdon: Routledge.

CID, J., y MARTí, J. (2012). Turning points and returning points. Understanding the role of family ties in the process of desistance. European Journal of Criminology 9(6), 603-620.

Cid, J., Pedrosa, A., Ibàñez, A. y Martí, J. (2021). Does the experience of imprisonment affect optimism about reentry? The Prison Journal, 101(1), 80-101.

CID, J. y TÉBAR, B. (2010). Spain. En: N. Padfield, D. van Zyl Smit, y F. Dünkel (Eds.), Release from prison. European policy and practice, (pp. 358-392). Cullompton: Willan Publishing.

Cutiño, S. (2015). Algunos datos sobre la realidad del tratamiento en las prisiones españolas. Revista Electrónica de Ciencia Penal y Criminología, 17, 1-41.

Doekhie, J., Dirkzwager, A., y Nieuwbeerta, P. (2017). Early attempts of desistance form crime: prisoners' prerelease expectations and their postrelease criminal behavior. Journal of Offender Rehabilitation, 56(7), 473-493.

DÜNKEL, F. (2017). European penology: the rise and fall of prison population rates in Europe in times of migrant crises and terrorism. European Journal of Criminology, 14(6), 629-653.

DÜnKel, F., Kestermann, C., y ZolondeK (2006). International study on women's imprisonment. Current situation, demand analysis and «best practice». Greifswald: University of Greifswald (Department of Criminology). (Recuperado de: https://rsf.uni-greifswald.de/ storages/uni-greifswald/fakultaet/rsf/lehrstuehle/ls-duenkel/Reader_ womeninprison.pdf).

EnJuanes, J. (2020). Hacia la construcción de las bases de un modelo de ejecución penal en base al concepto de ciudadanía activa. Estudios de tres casos en el sistema de ejecución penal español y catalán. (Tesis doctoral). (Recuperada de: https://tesisenred.net/ handle $/ 10803 / 668815 \#$ page $=1)$.

Gallego, M., Ríos, J., y Cabrera, P. (2010). Andar $1 \mathrm{Km}$ en línea recta. La cárcel del Siglo XXI que vive el preso. Madrid: Universidad Pontificia de Comillas. 
García-España, E. (2012). Las otras poblaciones presas: Mujeres y extranjeros. Revista de Derecho penal y Criminología, 7, 407-422.

García-España, E. y Díez-Ripollés. J. L., (Dirs.) (2012). Realidad y políticas penitenciarias. Valencia: Tirant lo Blanch.

Giménez-Salinas, E., Riera, J., Botella, L. y Marteache, N. (2006). L'opinió de les dones recluses a Cataluña sobre l'encarcerament. Justidata, 45, 1-16.

GonZÁLEZ, I. (2012). La cárcel en España: mediciones y condiciones del encarcelamiento. Revista de Derecho Penal y Criminología, 8, 351-402.

Howerton, A, Burnett, R, Byng, R., y Campbell, J. (2009). The consolation of going back to prison: What 'revolving door' prisoners think of their prospects. Journal of Offender Rehabilitation, 48, 439-461.

IBÁÑEZ, A. (2019). Progresar hacia el régimen abierto: la visión de los profesionales. Revista Española de Investigación Criminológica, 17, 1-28.

JimÉnez-BAutista, F. (2016). Percepciones de las mujeres en un espacio cerrado. Las prisiones en España. Regions \& Cohesion, 6(2), 59-84.

Jonson, C; Cullen, F (2015). Prisoner reentry programs. Crime and Justice. An annual Review of Research, 44, 517-568.

LERMAN, A. (2009). The people prisons make: effects of incarceration on criminal psychology. En S. Raphael y M. Stoll (Eds). Do prisons make us safer? (pp. 151-176) New York: Russell Sage Foundation.

Liebling, A. (2004). Prisons and their moral performance. A study of values, quality and prison life. Oxford: Clarendon Press.

Liebling, A., Laws, B., Lieber, E., Auti, K.,Schmidt, B., Crewe, B., Gardom, J., Kant, D., y Morey, M. (2019). Are hope and possibility achievable in prison?. Howard Journal of Crime and Justice, 58(1), 104-126.

Listwan, S., Sullivan, C., Agnew, R., Cullen, F., y Colvin, M. (2011). The pains of imprisonment revisited: the impact of strain on inmate recidivism. Justice Quarterly, 30(1), 144-168.

MAcKenzIE, D. (2006). What work in corrections. Reducing the criminal activities of offenders and delinquents. New York: Cambridge University Press.

Mapelli, B., Herrera, M., y Sordi, B. (2013). La exclusión de las excluidas. ¿Atiende el sistema penitenciario a las necesidades de género?: Una visión andaluza. Estudios Penales y Criminológicos, 33, 59-95.

Martí, J., y Cid, J. (2015). Encarcelamiento, lazos familiares y reincidencia: explorando los límites del familismo. Revista Internacional de Sociología, 71(1), 1-13. 
Navarro, C. (2018). El encarcelamiento femenino. Barcelona: Atelier.

Navarro, C., Ramos, F., Reynal, N., Líbano, A. y Ruiz, C. (2011). La conflictivitat als centres penitenciaris catalans. Barcelona: Centro de Estudios Jurídicos y Formación Especializada.

Pedrosa, A (2019). ¿A quién dejamos atrás? Revista Española de Investigación Criminológica, 17, 1-24.

Pozo, F., Navarro, M., NAKahira, M., y CutiÑo, S. (2018). Cara a cara con la cárcel. La visión de los presos sobre sus condiciones de custodia y resocialización en un centro penitenciario. Encrucijadas. Revista Crítica de Ciencias Sociales, 16, 1-24.

PRATT, J., y ERIKSSON, A, (2011). 'Mr. Larsson is walking out again'. The origins and development of Scandinavian prison systems. Australian \& New Zealand Journal of Criminology, 44(1), 7-23.

REDONDo, S. (2017). Evaluación y tratamiento de los delincuentes. Jóvenes y adultos. Madrid: Pirámide.

ReITER, K., Sexton, L., y Sumner, J, (2018). Theoretical and empirical limits of Scandinavian exceptionalism: Isolation and normalization in Danish prisons. Punishment \& Society, 20 (1), 92-112.

Ríos, J., y CABReRa, P. (1998). Mil voces presas. Madrid: Universidad Pontificia de Comillas.

Ríos, J., y Cabrera, J. (2002). Mirando el abismo. El régimen cerrado. Madrid: Universidad Pontificia de Comillas.

Rodríguez-Menés, J., LarRauri, E., y GÜerri, C. (2018). Percepción de la calidad de vida en prisión. La importancia de una buena organización y un trato digno. Revista Internacional de Sociología, 76 (2), 1-20.

TÉBAR, B. (2005). El modelo español de libertad condicional. Pamplona. Aranzadi.

Travis, J. (2005). But they all come back. Facing the challenges of prisoner reentry. Washington: The Urban Institute Press.

Van Zyl Smit, D. y Snacken, S. (2009). Principles of European Prison Law and Policy. Penology and Human Rights. Oxford: Oxford University Press.

VISHER, C., y O'CONNELL, D. (2012). Incarceration and inmates' selfperceptions about returning home. Journal of Criminal Justice, 40(5), 368-393. 